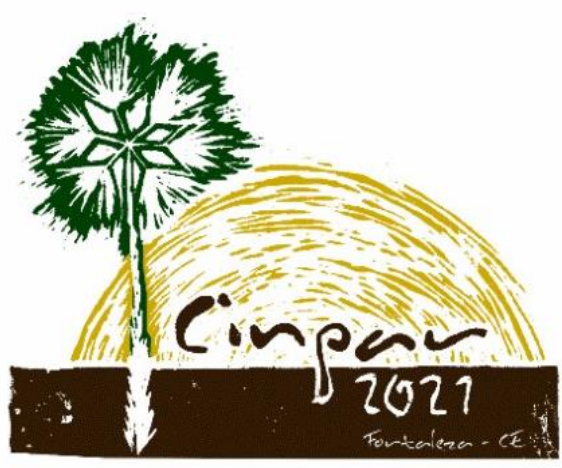

XVII Congresso Internacional sobre Patologia e Reabilitação das Construções

XVII Congreso Internacional sobre Patología y Rehabilitación de las Construcciones

XVII International Conference on Pathology and Constructions Rehabilitation

FORTALEZA (Brasil), 3 a 5 de junho de 2021

https://doi.org/10.4322/CINPAR.2021.109

\title{
Aplicação da Norma de Inspeção Predial em uma edificação de autoconstrução - Estudo de Caso: Curvelo/MG
}

\section{Application of Building Inspection Standard in a self-construction building - Case Study: Curvelo/MG}

\author{
Flávia Cota GUEDES ${ }^{1}$, Isabela Geovana Teixeira SOUZA ${ }^{2}$, Isabela da Silva VEIGA ${ }^{3}$, Marcos de Paulo RAMOS ${ }^{4}$ \\ Thiago Pena BORTONE ${ }^{5}$, Rachel Jardim MARTINI ${ }^{6}$ \\ ${ }^{1}$ CEFET/MG, Curvelo, Brasil, flavia_cota@hotmail.com \\ ${ }^{2}$ CEFET/MG, Curvelo, Brasil, isabela_tsouza@yahoo.com \\ ${ }^{3} \mathrm{CEFET} / \mathrm{MG}$, Curvelo, Brasil, isabeladasilvaveiga@gmail.com \\ ${ }^{4}$ CEFET/MG, Curvelo, Brasil, marcos.ramos@cefetmg.br \\ ${ }^{5}$ CEFET/MG, Curvelo, Brasil, thiago.bortone@cefetmg.br \\ ${ }^{6} \mathrm{CEFET} / \mathrm{MG}$, Curvelo, Brasil, martini@cefetmg.br
}

\begin{abstract}
Resumo: As manifestações patológicas prediais podem causar grandes prejuízos financeiros e até mesmo comprometer a segurança dos usuários. Essas falhas e anomalias poderiam, contudo, ser evitadas com medidas simples que se iniciam com a realização da Inspeção Predial. Tal processo tem o objetivo de auxiliar na gestão da edificação e contribui com a mitigação de riscos técnicos e econômicos relacionados à perda do desempenho da estrutura. O presente trabalho tem como objetivo realizar a Inspeção Predial em uma edificação de autoconstrução, utilizando a normativa vigente da Associação Brasileira de Normas Técnicas (ABNT). Para o seu desenvolvimento, foram adotadas todas as etapas recomendadas pela norma, principalmente aquelas relacionadas à: anamnese (visando a identificação das características construtivas), classificação das irregularidades constatadas e recomendações necessárias para restaurar ou preservar o desempenho durante a vida útil da edificação. Diante da análise realizada, constata-se que a edificação inspecionada possui inconformidades técnicas e construtivas. Os principais problemas detectados estão relacionados à fissuração e umidade. Foi encontrada uma trinca, possivelmente causada por recalque diferencial, em virtude de um reservatório de água instalado em cima do banheiro. Se o recalque não estiver estabilizado, pode comprometer a segurança dos usuários. Por fim, independentemente da gravidade, recomenda-se que sejam realizadas as intervenções sugeridas o quanto antes, através da atuação de profissionais especializados, para sanar as irregularidades e evitar a evolução e o surgimento de novas manifestações patológicas.
\end{abstract}

Palavras-chave: Manifestações patológicas, inspeção predial, edificações de autoconstrução.

Abstract: The pathological manifestations of buildings can cause great financial losses and even compromise the safety of users. These failures and anomalies could, however, be avoided with simple measures that start with the completion of the Building Inspection. This process is intended to assist in the management of the building and contributes to the mitigation of technical and economic risks related to the loss of the structure's performance. This paper aims to carry out the Building Inspection in a self-constructed building and for that purpose, the current regulations of the Brazilian Association of Technical Standards (ABNT) were used. For its development, all the steps recommended by the standard were adopted, mainly those related to: anamnesis (aiming at the identification of the construction characteristics), classification of 
the irregularities found and recommendations necessary to restore or preserve the performance during the useful life of the building. In view of the analysis carried out, it appears that the inspected building has technical and constructive non-conformities. The main problems detected are related to cracking and moisture. A crack was found, possibly caused by differential settlement, due to a water tank installed on top of the bathroom. If repression is not stabilized, it can compromise the safety of users. Finally, regardless of the severity, it is recommended that the suggested interventions be carried out as soon as possible, through the work of specialized professionals, to remedy the irregularities and prevent the evolution and the appearance of new pathological manifestations.

Keywords: Pathological manifestations, building inspection, self-construction buildings.

\section{Introdução}

O expressivo e desordenado acréscimo populacional nas cidades, ocorrido com êxodo rural, principalmente nas décadas de 1950 a 1980, definiu o perfil que as cidades brasileiras possuem hoje, mas também causou problemas sociais como falta de empregos e de moradias (ALVES et al., 2011). Uma saída para esta questão foi a construção de casas pelos próprios moradores. Balthazar $(2012$, p.35) define autoconstrução como "uma modalidade construtiva autônoma, em que o morador empreende a provisão de sua própria casa desde a escolha do terreno, planejamento, definição de projeto e execução da obra". Como afirmam Silva e Máximo (2017), este tipo de construção pode representar dois tipos de problemáticas: uma na esfera sócio-política, e outra na esfera técnica, devido à baixa qualidade espacial e às más condições de conforto ambiental e segurança.

Conforme Souza (2017), em edificações autoconstruídas não há planejamento prévio especializado e todas as decisões construtivas são tomadas na obra, baseadas no conhecimento popular e na experimentação prática e não na técnica. A falta de conhecimento técnico resulta no aparecimento de diversas manifestações patológicas que causam perda de desempenho e reduzem o tempo de vida útil da edificação. Além disso, os residentes muitas vezes não têm conhecimento da importância de se realizar manutenções periódicas e do papel da Inspeção Predial na conservação do local. Essa última atividade é atualmente regulamentada pela norma NBR 16747: Inspeção predial - Diretrizes, conceitos, terminologia e procedimentos (ABNT, 2020).

Essa norma define a Inspeção Predial como "o processo de avaliação das condições técnicas, de uso, operação, manutenção e funcionalidade da edificação e de seus sistemas e subsistemas construtivos, de forma sistêmica e predominantemente sensorial (na data da vistoria), considerando os requisitos dos usuários" (ABNT, 2020, p.3).

O presente trabalho consistiu na realização da Inspeção Predial, de acordo com os requisitos da NBR 16747 (ABNT, 2020), em uma residência localizada no Município de Curvelo/MG, onde foram verificados todos os aspectos de uso e manutenção da edificação, buscando orientar a conservação e o desempenho adequado dos seus sistemas.

\section{Inspeção predial}

A trajetória da Inspeção Predial, de acordo com Neves e Branco (2009), iniciou-se no Brasil em 1999. No ano de 2001, o IBAPE-SP lançou a primeira norma técnica de inspeção predial, um avanço muito importante para as atividades na área (NEVES e BRANCO, 2009). Em 2012, o IBAPE Nacional lançou a Norma de Inspeção Predial Nacional (IBAPE, 2012). Em 2020 foi lançada pela Associação Brasileira de Normas Técnicas, a NBR 16747, onde são estabelecidos os critérios e as etapas para que a Inspeção Predial seja sistemática e metodológica (ABNT, 2020).

Qualquer etapa do processo construtivo pode contribuir para o surgimento de manifestações patológicas. Esses problemas, quando surgem, devem ser identificados e tratados o quanto antes para não comprometerem a segurança, a qualidade e o desempenho do edifício. De acordo com Lima et al. (2017), a falta de programas de manutenção das edificações é uma das principais causas de deterioração precoce do ambiente construído. Souza et al. (2020) afirmam ainda que toda edificação deve ter um programa de

Aplic. da Norma de Inspeção Predial em edificação de autoconstrução - Estudo de Caso: Curvelo/MG 
manutenção específico, com considerações sobre projeto, memoriais descritivos e manuais de uso e operação. No entanto, pelas características das autoconstruções, edificaçõesdeste tipo não costumam possuir nenhum tipo de programa que oriente a manutenção predial.

A Inspeção Predial pode ser conceituada como um processo auxiliar na gestão da edificação para mitigar riscos técnicos e econômicos ligados ao desempenho da edificação (ABNT, 2020). O seu objetivo é constatar o estado atual da edificação na data da vistoria e sua finalidade é instruir a gestão do uso, operação e manutenção, levando em consideração os requisitos dos usuários. De forma que fica evidente que a Inspeção periódica visando manutenção é uma peça importante para a vida útil da edificação.

De acordo com a NBR 16747 (ABNT, 2020), as etapas da inspeção predial são divididas em: levantamento e análise dos dados e documentação, anamnese, vistoria da edificação, classificação das irregularidades e as recomendações pertinentes, organização das prioridades, avaliação da manutenção e do uso e a elaboração do laudo técnico.

\section{Metodologia}

\section{1 Estudo de caso}

O presente trabalho apresenta o estudo feito em uma residência unifamiliar, autoconstruída e de único pavimento, localizada no Município de Curvelo/MG. Esta edificação foi erguida em concreto armado, com alvenaria de vedação de tijolos cerâmicos e tem idade aproximada de 50 anos.

Trata-se de um exemplo de edificação autoconstruída em que se pode discutir a respeito da relevância das normas técnicas e de profissionais qualificados para se minimizar a ocorrência de anomalias e falhas construtivas. Vale salientar que essa construção foi executada a bastante tempo, antes mesmo da publicação de muitas das normas hoje existentes. Além disso, como é comum nas edificações autoconstruídas, raramente há o acompanhamento de um profissional habilitado para orientar a execução dos trabalhos, de construção e reformas, o que, apesar da experiência dos construtores, pode levar a falhas construtivas que posteriormente resultam no surgimento de manifestações patológicas mais graves.

As manifestações patológicas podem ser decorrentes de diversos fatores como, por exemplo, práticas inadequadas de construção e baixa qualidade dos materiais (NOVELLE,2018). Com isso, se torna ainda mais importante a realização das Inspeções Prediais periódicas.

\subsection{Metodologia de inspeção em edificações}

A metodologia empregada seguiu as prescrições da NBR 16747 (ABNT, 2020). O gráfico de processos abaixo (Figura 1) resume a metodologia adotada.
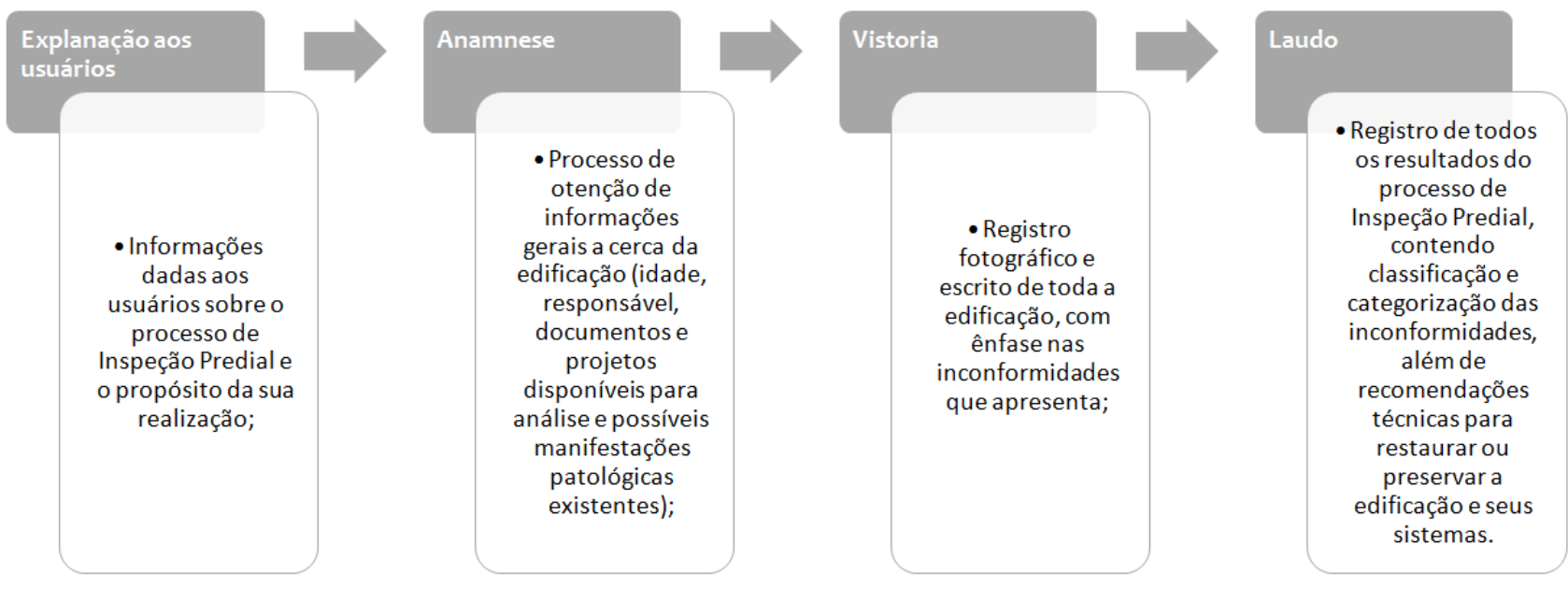

Figura 1 - Metodologia da inspeção

Fonte: Autores 


\subsection{Elaboração do Laudo}

O laudo de Inspeção Predial contém informações como: identificação do solicitante, descrição da edificação, análise dos dados e das documentações solicitadas e disponibilizadas, descrição da metodologia adotada, entre outros.

A norma técnica vigente pede que as irregularidades constatadas sejam classificadas em prioridades de acordo com o risco que representam aos usuários e ao meio ambiente. Resumidamente, o documento traz três níveis de prioridade. As inconformidades compreendidas na Prioridade 1 são aquelas que exigem intervenção imediata, uma vez que podem trazer risco à saúde e à segurança dos moradores e do meio ambiente; já a Prioridade 2 representa aqueles problemas que, apesar de terem impacto negativo sobre a funcionalidade da edificação e seus sistemas, não apresentam risco aos usuários ou ao meio ambiente; por fim, as ações exigidas no nível de Prioridade 3 não requerem urgência, pois representam apenas pequenos prejuízos estéticos e não causam impacto na funcionalidade ou risco aos usuários (ABNT, 2020).

\section{Resultados}

\subsection{Análise das principais manifestações patológicas encontradas}

Diversas manifestações patológicas foram constatadas na edificação em estudo. Como é comum em grande parte das habitações com o mesmo tipo e método construtivos, as manifestações patológicas mais frequentes foram trincas e problemas com umidade. Fissuras e trincas constituem o tipo mais comum de manifestação patológica encontrados nas edificações e é capaz de afetar a estética, a durabilidade e até as características estruturais do empreendimento (NUNES et al. 2017). Já a presença constante de umidade pode causar a degradação da alvenaria e do concreto, além de favorecer a proliferação de fungos e bactérias e acarretar, consequentemente, problemas de saúde. A seguir são apresentadas as principais falhas e anomalias construtivas presentes na edificação.

\subsection{1 - Corrosão do material do portão}

A Figura 2 mostra a oxidação da parte inferior do portão de garagem. A corrosão é o resultado da oxidação do metal do portão que resulta na sua degradação e que, se não for tratado, progride até sua destruição total. Dentre os meios mais utilizados, por ser barato e de fácil utilização, está a pintura, que inibe a corrosão, desde que o preparo e o condicionamento da superfície e a aplicação propiamente dita estejam corretos (OLIVEIRA, 2012).

Trata-se de uma falha de manutenção ocasionada provavelmente pela pintura inadequada do elemento e contato constante com intempéries.

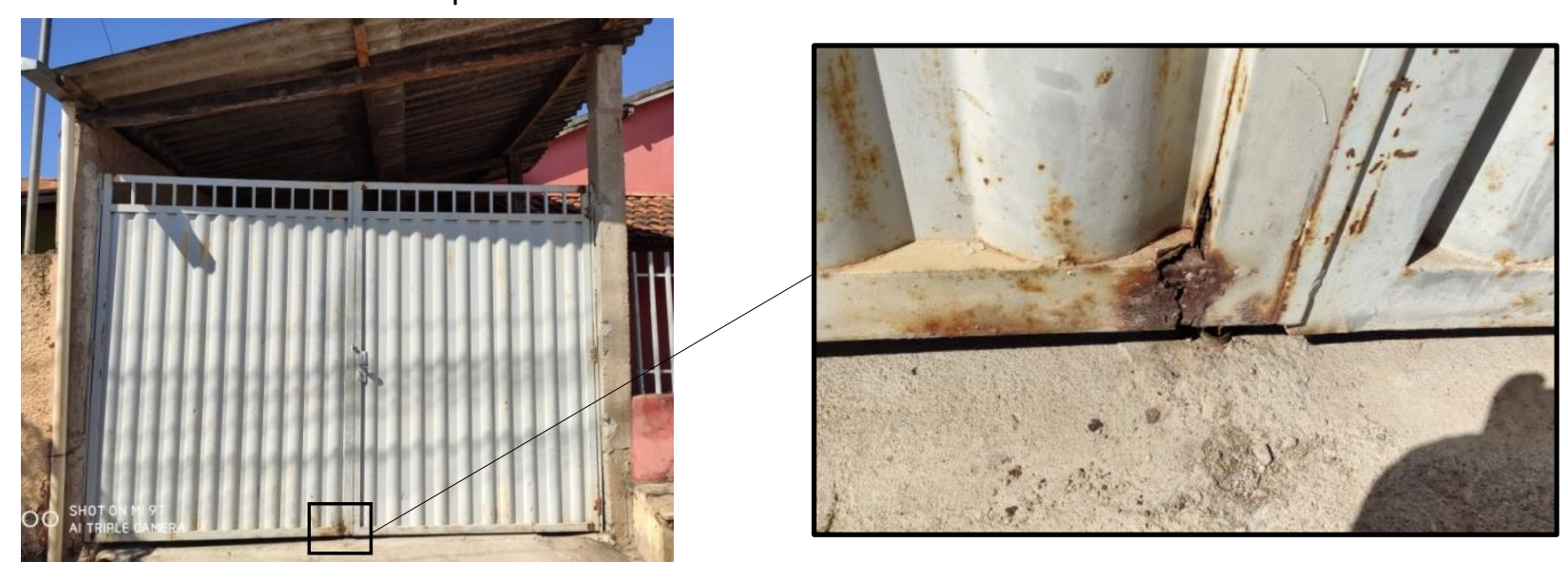

Figura 2 - Portão de garagem, com parte oxidada em detalhe Fonte: Acervo fotográfico dos autores 


\subsection{2 - Trincas diagonais}

O lado externo da parede adjacente ao banheiro da casa apresenta uma trinca (Figura 3), possível característica de recalque diferencial, que pode ter sido intensificada pela sobrecarga causada pela caixa d'água presente no local. Essa trinca se manifesta, com menor intensidade, também no interior do imóvel.

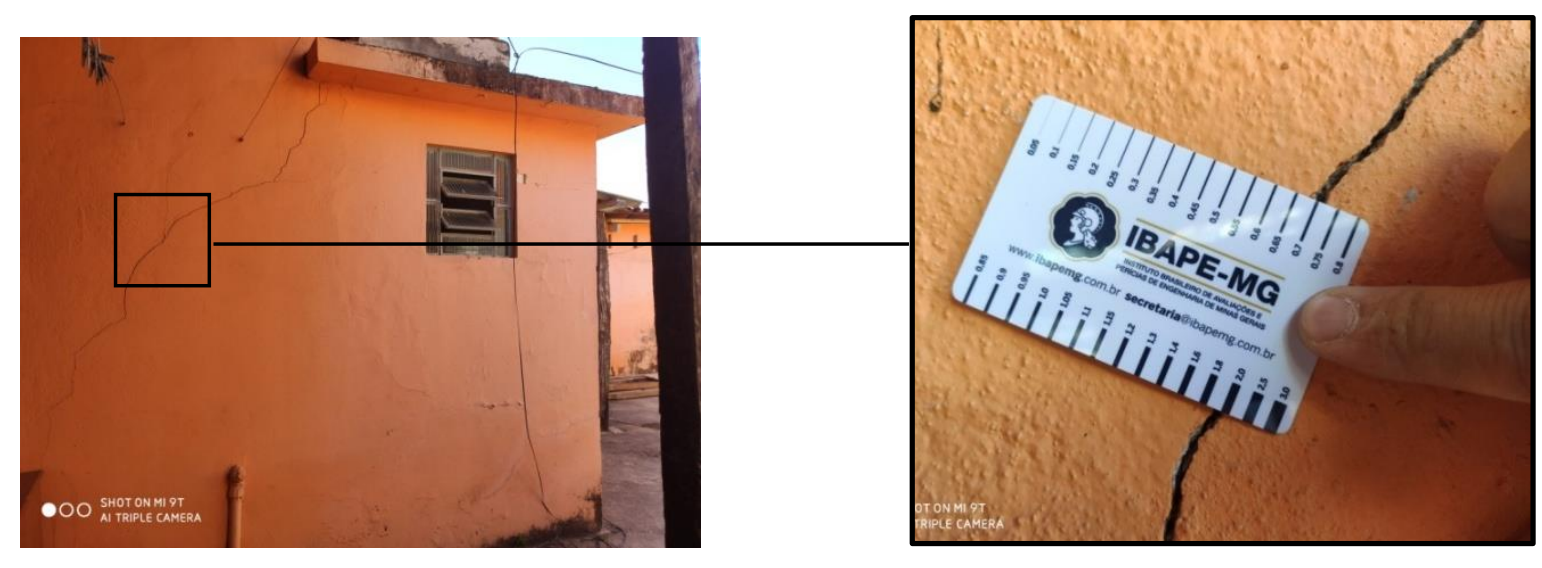

Figura 3 - Trinca na parede externa, com espessura em detalhe Fonte: Acervo fotográfico dos autores

\subsection{3 - Trinca vertical}

A Figura 4 mostra uma trinca vertical existente no encontro das paredes do banheiro e da cozinha, a qual demonstra uma possível falta de amarração entre essas paredes.

Como explica Magalhães (2004), a amarração é feita pela junção dos tijolos ou utilizando algum elemento metálico nas juntas de argamassa durante o assentamento, para garantir a amarração.

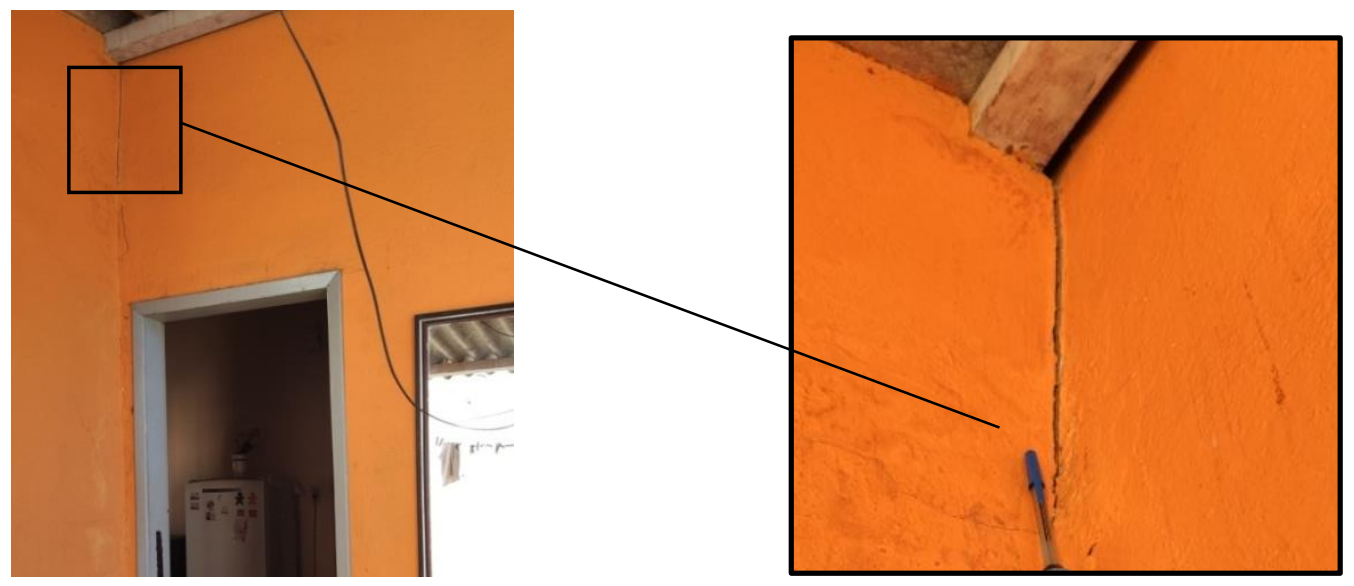

Figura 4 - Trinca no encontro das paredes, com espessura no detalhe Fonte: Acervo fotográfico dos autores

\subsection{4 - Infiltração na varanda}

A parede da varanda apresenta infiltração ascensional, vista na Figura 5, provocada pela umidade do solo, devido a uma provável falta de impermeabilização da fundação. $O$ excesso de umidade na região pode ter causado inclusive o desprendimento de parte do revestimento.

Esse tipo de infiltração se caracteriza pela presença de água do solo, tanto pelo aumento de umidade devido a fatores climáticos como pela presença da umidade de lençóis freáticos superficiais; a ascensão da água ocorre pela existência do fenômeno de capilaridade (VIEIRA, 2018).

Nota-se também manchas de umidade causadas pela passagem de água da chuva entre a parte superior da parede e o telhado, sinais de vedação insuficiente (ou ausência de rufo). 


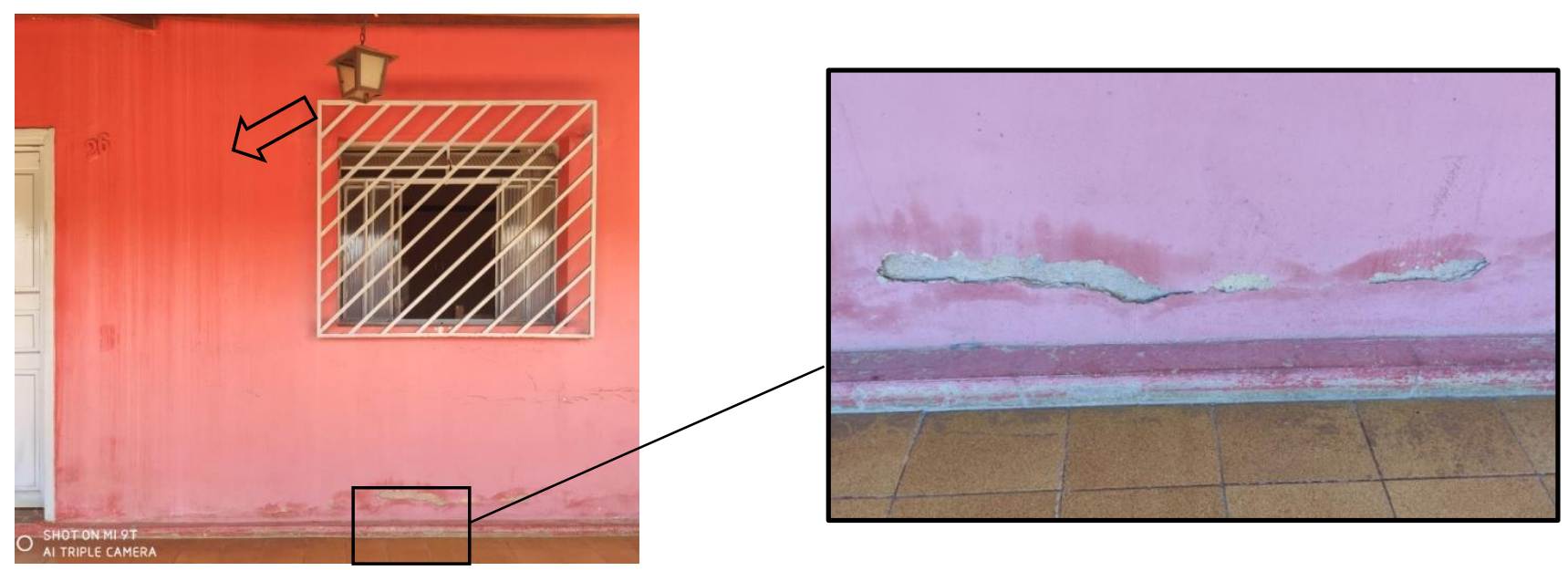

Figura 5 - Sinais de infiltração na parede, com infiltração ascendente em detalhe Fonte: Acervo fotográfico dos autores

\subsection{5 - Manchas de bolor e eflorescência}

A Figura 6 traz as manchas de bolore e florescência encontradas na parede do banheiro. Essa falha pode ter ocorrido por uma infiltração existente na laje e foi agravada pela umidade constante do ambiente.

A eflorescência é causada pela presença de água e de sais solúveis nas paredes, que se manifestam na superfície do elemento por causa da pressão hidrostática, ocasionando manchas, descolamento ou descoloramento da pintura, entre outros (BAUER,1994).

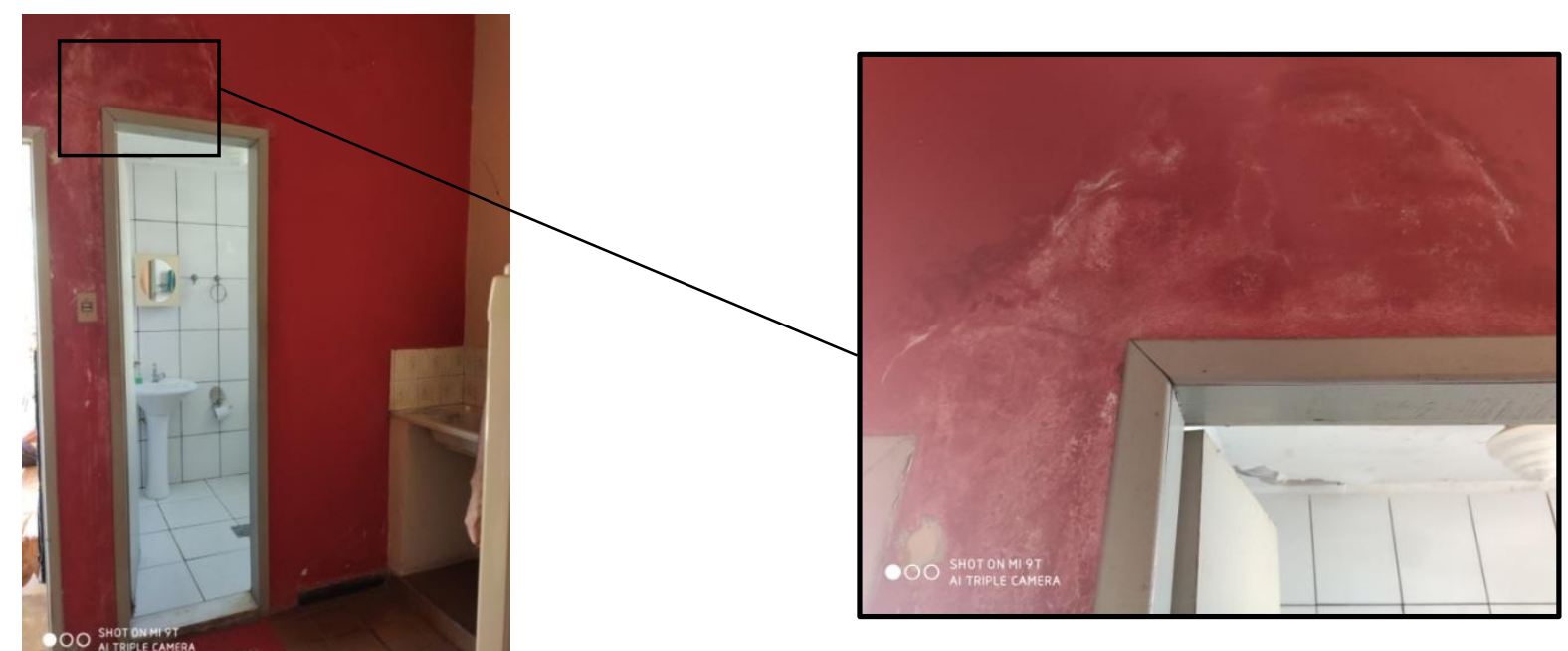

Figura 6 - Manchas de bolor na parede, com o ponto mais afetado em detalhe Fonte: Acervo fotográfico dos autores

\subsection{Análise dos resultados}

De acordo com a NBR 16747 (ABNT,2020), as falhas e anomalias encontradas devem ser classificadas em patamares de urgência, segundo as recomendações técnicas sugeridas para reparar cada problema.

O Quadro 1 mostra a lista de prioridades organizadas pela urgência e as recomendações técnicas sugeridas. 
Quadro 1 - Recomendações técnicas e ordem de urgência

\begin{tabular}{|c|c|c|c|c|c|}
\hline Elemento & Figura & Categoria & Prioridade & $\begin{array}{l}\text { Ordem } \\
\text { de } \\
\text { urgência }\end{array}$ & Recomendação técnica \\
\hline $\begin{array}{c}\text { Trincas } \\
\text { diagonais }\end{array}$ & 3 & $\begin{array}{l}\text { Anomalia } \\
\text { endógena }\end{array}$ & 1 & 10 & $\begin{array}{l}\text { Recomenda-se realizar um estudo aprofundado } \\
\text { para avaliar se a trinca está ativa e conforme o } \\
\text { resultado, realizar o reforço da estrutura ou da } \\
\text { fundação. }\end{array}$ \\
\hline $\begin{array}{c}\text { Trinca } \\
\text { vertical }\end{array}$ & 4 & $\begin{array}{l}\text { Anomalia } \\
\text { endógena }\end{array}$ & 2 & 20 & $\begin{array}{l}\text { Recomenda-se realizar a injeção da trinca. } \\
\text { Souza e Ripper (1998) aconselham o uso de } \\
\text { materiais rígidos como as resinas epóxidas, caso } \\
\text { a abertura seja passiva, ou flexíveis como as } \\
\text { resinas acrílicas, caso a trinca seja ativa. }\end{array}$ \\
\hline $\begin{array}{l}\text { Manchas de } \\
\text { bolor e } \\
\text { eflorescência }\end{array}$ & 6 & $\begin{array}{c}\text { Falha de } \\
\text { manutenção }\end{array}$ & 2 & 3 은 & $\begin{array}{l}\text { Deve-se primeiramente impermeabilizar e } \\
\text { providenciar uma cobertura para laje do } \\
\text { banheiro. Após sanada essa questão, fazer a } \\
\text { remoção de todo o revestimento contaminado, } \\
\text { até a exposição da alvenaria; aplicar argamassa } \\
\text { polimérica ou impermeabilizante; e então, } \\
\text { executar nova camada de revestimento. }\end{array}$ \\
\hline $\begin{array}{c}\text { Infiltração na } \\
\text { varanda }\end{array}$ & 5 & $\begin{array}{c}\text { Falha de } \\
\text { manutenção }\end{array}$ & 2 & 40 & $\begin{array}{l}\text { Como a impermeabilização da fundação na fase } \\
\text { de uso é impraticável, deve-se remover todo o } \\
\text { revestimento contaminado; aplicar argamassa } \\
\text { polimérica ou impermeabilizante; e por fim, } \\
\text { executar nova camada de revestimento. } \mathrm{Na} \\
\text { parte superior, substituir o rufo do telhado. }\end{array}$ \\
\hline $\begin{array}{l}\text { Oxidação do } \\
\text { portão }\end{array}$ & 2 & $\begin{array}{c}\text { Falha de } \\
\text { manutenção }\end{array}$ & 3 & 50 & $\begin{array}{l}\text { Realizar a recomposição do elemento, limpar } \\
\text { com auxílio de lixa; aplicar zarcão e tinta para } \\
\text { evitar aumento do problema. }\end{array}$ \\
\hline
\end{tabular}

\section{Conclusões}

Como era esperado, o estudo realizado mostrou diversas inconformidades existentes na edificação inspecionada. Estes mesmos problemas são encontrados com frequência em muitas residências com tipo construtivo (autoconstrução) e idade semelhantes a esta, o que mostra que a falta de conhecimento técnico e o não seguimento das normas técnicas de construção, mesmo em edificações de pequeno porte, podem influenciar fortemente no seu desempenho ao longo dos anos. Apesar da quantidade de anomalias e falhas construtivas observadas, apenas uma apresenta significativo grau de criticidade a ponto de colocar em risco a segurança dos usuários, contudo, é importante conscientizá-los, e à comunidade em geral, a respeito da importância do emprego profissionais qualificados no exercício da Construção Civil.

Os resultados obtidos mostram a importância de se realizar as inspeções periódicas com a finalidade de reduzir falhas e anomalias e os custos provenientes de reparos, quando necessários. Em construções autoconstruídas isso não é uma exceção, apesar de muitos estudos estarem voltados para unidades de interesse social, este trabalho demonstrou que também é importante o estudo em unidades autoconstruídas para catalogar e mostrar a importância dessas inspeções aos residentes, a fim de difundir o conhecimentos sobre o ato da manutenção preventiva.

\section{Agradecimentos}

Agradecemos ao Cefet/MG, ao LAR - Laboratório Avaliação e Reabilitação de Ambiente Construído do CEFET-MG - Campus Curvelo e à equipe do Projeto de Extensão "Inspeção predial e análise de anomalias e falhas construtivas em edificações pelo incentivo e apoio no desenvolvimento deste trabalho. Agradecemos 
também aos proprietários da residência inspecionada por nos permitirem o acesso e se colocarem a disposição para qualquer auxílio necessário.

\section{Referências Bibliográficas}

Alves, E.; Souza, G. S.; Marra R. Êxodo e sua contribuição à urbanização de 1950 à 2010. Revista de política Agrícola, 2011, v. 20, n. 2, p. 80-88.

Associação Brasileira de Normas Técnicas. NBR 16747: Inspeção predial - Diretrizes, conceitos, terminologia e procedimento. Rio de Janeiro, 2020.

Balthazar, R. D. S. A permanência da autoconstrução: um estudo de sua prática no Município de Vargem Grande Paulista. 2012. 147 f. Dissertação (Mestrado em Arquitetura) - Faculdade de Arquitetura e Urbanismo da Universidade de São Paulo, São Paulo.

Bauer, L.A.F. Materiais de construção. Rio de Janeiro: Livros Técnicos e Científicos. Editora S.A., 5.ed, 1994.

Instituto Brasileiro de Avaliações e Perícias de Engenharia. Norma de Inspeção Predial Nacional. São Paulo, 2012.

Lima, V. N.; Landim, G. L.; Rocha, L de M. Causas patológicas na construção civil: estudo de caso em uma construtora do Município de Juazeiro do Norte. In: CONGRESSO INTERNACIONAL SOBRE PATOLOGIA E REABILITAÇÃO DE ESTRUTURAS, 13., 2017, Crato-CE. Anais... Crato: CINPAR, 2017, p. 135-147.

Magalhães, E. F. de F. Fissuras em alvenarias: Configurações típicas e levantamento de incidências no estado do Rio Grande do Sul. 2004. Dissertação (Mestrado em Engenharia) - Universidade Federal do Rio Grande do Sul, Porto Alegre.

Neves, D. R. R.; Branco, L. A. M. N. Estratégia de inspeção predial. Belo Horizonte: Construindo, 2009, v. 1, n. 2, p. 12-19.

Novello, B. S. Estudo de caso de construção habitacional comunitária para baixa renda na cidade do Rio de Janeiro. 2018. 119 f. Trabalho de Conclusão de Curso (Graduação em Engenharia Civil) - Universidade Federal do Rio de Janeiro, Rio de Janeiro.

Nunes, M. A. E.; Vaz, B. H. A.; Tavares, J. C. Monitoramento de fissuras em uma residência unifamiliar. In: CONGRESSO INTERNACIONAL SOBRE PATOLOGIA E REABILITAÇÃO DE ESTRUTURAS, 13., 2017, Crato-CE. Anais... Crato: CINPAR, 2017, p. 113-121.

Oliveira, A. R. de. Corrosão e tratamento de superfície. Belém: IFPA; Santa Maria: UFSM, 2012. 104p.

Silva, E. M. F.; Máximo, F. R. C. C. Análise de aspectos construtivos e de conforto ambiental em residências autoconstruídas no Sertão Central Cearense. In: CONGRESSO INTERNACIONAL DA DIVERSIDADE DO SEMIÁRIDO, 2., 2017, Campina Grande-PB. Anais... Campina Grande: Editora Realize, 2017.

Souza, I. G. T.; Guedes, F. C.; Ramos, M. de P.; Bortone, T. P.; Martini, R.; Ferreira, L. Aplicação da Norma de Inspeção Predial Nacional (IBAPE) em edificações populares - Estudo de caso: Curvelo-MG. In: CONGRESSO BRASILEIRO DE PATOLOGIA DAS CONSTRUÇÕES, 4., 2020, Fortaleza-CE. Anais... Fortaleza: ALCONPAT, 2020, p. 2567-2576.DOI: http://dx.doi.org/10.4322/CBPAT.2020.248.

Souza, M. F. e. Modos de vida e modos de habitar em moradias autoconstruídas : um estudo nos bairros Nova Viçosa e Posses, em Viçosa-MG. 2017. Trabalho de conclusão de curso (Pós-graduação em arquitetura e urbanismo) - Viçosa.

Souza, V. C. de; Ripper, T. Patologia, Recuperação e Reforço de Estruturas de Concreto. 1. ed. São Paulo: Pini, 1998.

VIEIRA, F. de S. Estudo de avaliação financeira para reforma de uma edificação residencial em llicínea - MG com incidência de infiltração em paredes. 2018. Trabalho de conclusão de curso(Graduação em Engenharia Civil) - Centro Universitário do Sul de Minas, Varginha. 